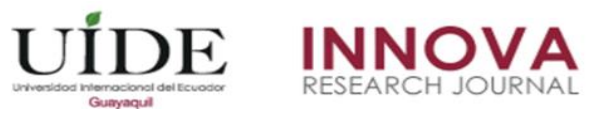

INNOVA Research Journal, ISSN 2477-9024

(Marzo, 2017). Vol. 2, No.3 pp. 13-26

DOI: https://doi.org/10.33890/innova.v2.n3.2017.129

URL: http://revistas.uide.edu.ec/index.php/innova/index

Correo: innova@uide.edu.ec

\title{
Ciudadanía y globalización. El reto de un nuevo modelo para el pleno reconocimiento de los derechos de las personas
}

\section{Citizenship and globalization. The challenge of a new model for the full recognition of the rights of persons}

\author{
Karla Elizabeth Andrade Quevedo \\ Universidad Internacional SEK, Ecuador
}

Autor para correspondencia: karla.andrade.der@uisek.edu.ec

Fecha de recepción: 13 de Diciembre de 2016 - Fecha de aceptación: 20 de Febrero de 2017

Resumen: El modelo de ciudadanía ligado al Estado-nación que manejamos a día de hoy, ha agotado su capacidad de acción en un mundo globalizado donde el demos ya no es homogéneo ni responde a factores étnico-culturales. La realidad actual ha convertido al concepto de ciudadanía en un elemento de exclusión que impide a las personas el pleno ejercicio de los derechos fundamentales por el simple hecho de no tener un vínculo territorial o de sangre con el Estado en el que reside. Esto ha provocado la aparición de ciudadanos de segunda clase que, a pesar de formar parte de un Estado y de asumir todas las obligaciones de los nacionales, no gozan de los mismos derechos. Por lo tanto, aquello tiene que cambiar; es preciso revolucionar el concepto de ciudadanía y atarlo a factores más reales y consecuentes. Desligarlo de la nacionalidad y permitir que su contenido material se entregue a todos quienes realmente conforman un Estado. Solo la ciudadanía inclusiva permite el reconocimiento pleno de los derechos a las personas, garantiza la legitimación democrática y crea un verdadero vínculo entre la persona y el Estado en el que reside. La única posibilidad de avanzar en el reconocimiento de derechos de las personas y ser congruentes con la globalización, es caminar hacia la ciudadanía inclusiva.

Palabras clave: ciudadanía; inclusión; derechos; nacionalidad; globalización

\begin{abstract}
The current Nation-state model of citizenship that we manage has exhausted its action capability in this globalized world where the demos is no longer homogeneous, neither responds to ethnic and cultural factors. Today's reality has converted the concept of citizenship in an exclusion element that inhibits people to fully exercise fundamental rights, just because they don't have a territorial or blood link to the State where they live. This has provoked the appearance of second class citizens who don't have the same rights even though they are part of the State and assume every obligation as citizens. Therefore, this has to change; a revolution in the citizenship concept is needed and we have to tie it up to more real and significant factors. Untie it from nationality and allow its material content to grow and extend to everyone who is really part of a State. Only an inclusive citizenship model allows full rights recognition, guarantees democratic legitimation and creates a real link between people and their State of residence. The only chance to move forward in fundamental rights recognition and be congruent with globalization needs, is to walk towards inclusive citizenship.
\end{abstract}

Key Words: citizenship; inclusion; rights; nationality; globalization 


\section{Introducción}

La noción de ciudadanía que manejamos en la actualidad es el producto de una larga y compleja evolución. A lo largo de la historia, la ciudadanía ha tenido múltiples alcances y se ha visto enmarcada en muy diversos contextos, pero el actual, definitivamente puede ser catalogado como el más complejo. La globalización ha convertido el mundo en "una plaza grande, en un ágora, donde se mueven e interactúan gentes de todas las razas y culturas, y en un gran mercado en el que libremente transitan capital, tecnología, recursos, empresas y productos" (Calvo, 2006, Pg. 30). Por lo que los Estados se han visto en la necesidad de evolucionar y abrir sus puertas a los grandes retos que trae la globalización. Uno de estos, la intensa movilidad humana y sus efectos sobre los derechos de quienes, siendo extranjeros, viven e interactúan activamente dentro del Estado.

El concepto actual de ciudadanía, ligado a exclusivamente a la nacionalidad, está agotando su capacidad de maniobra. Su definición, elaborada a mediados del siglo pasado, está relacionada completamente a la pertenencia a un Estado-nación concreto, de tal forma que una persona solo puede ser ciudadano en el territorio del Estado al cual esté vinculado ya sea por ius solis o ius sanguinis; pero la globalización y los procesos migratorios han propiciado nuevas formas de vinculación de las personas un Estado, relacionadas a factores fácticos más reales como la residencia.

Las circunstancias actuales unos obligan a cuestionar el concepto de ciudadanía excluyente que manejan los Estados y buscar un modelo que garantice realmente el pleno reconocimiento de los derechos de las personas que viven y forman parte de los Estados, las sociedades y el mundo actual. No obstante, este constituye un difícil reto, pues la vinculación de la ciudadanía con la nacionalidad está muy arraigada; más aún ahora con las tendencias políticas conservadoras tomando fuerza y los nacionalismos recobrando espacios en los principales países receptores de flujos migratorios.

En este artículo estudiaremos el largo proceso de evolución que ha tenido el concepto de ciudadanía y su estrecha vinculación con la nacionalidad para analizar los escenarios reales que éste concepto está provocando en la actualidad y a partir de ahí proponer un modelo más justo e inclusivo, que supera las concepciones tradicionales y busca el pleno reconocimiento de los derechos de las personas.

\section{Evolución histórica del concepto de ciudadanía.}

El nacimiento del concepto de ciudadanía data de la antigua Grecia, hace unos 2.500 años aproximadamente. Aristóteles, fue el primero en formular una tesis sobre ciudadanía, pues para él, al ser el hombre un animal político que requería de la convivencia para sobrevivir, se convertía en un ser que puede mandar y dejarse mandar, por lo que, para él, el ciudadano se caracterizaba, principalmente, por su participación activa en la administración de justicia y gobierno de la polis. No obstante, estas importantes responsabilidades de participación en la vida pública estaban limitadas solamente a un grupo reducido de "ciudadanos", ya que la ciudadanía era un estatus restringido y privilegiado al que no podía acceder toda la población. Las mujeres, 
los esclavos y los extranjeros o metecos se encontraban excluidos de la ciudadanía. (Horrach, 2009)

Con el auge del Imperio Romano, el concepto de ciudadanía adoptó un nuevo modelo que se distanció del griego y tomó nuevas características. Según el modelo romano inicial, la condición de ciudadano era un estatus que le permitía al individuo vivir bajo la protección del derecho romano. Se transmitía por vía paterna y conllevaba de una serie de derechos y obligaciones, como el pago de impuestos y la posibilidad de votar, así como tener un escaño en la asamblea o ser elegidos como magistrados. Cabe mencionar que, en la práctica, debido a que el poder se encontraba sumamente concentrado en la figura del gobernante, la capacidad política real de los ciudadanos era muy escasa dentro de la Asamblea popular; por lo que, en realidad, en sus inicios, la ciudadanía brindaba atributos de reconocimiento social más que derechos de participación real y efectiva en el ejercicio político (Horrach, 2009).

Con la llegada de la Edad Media, el concepto de ciudadanía cambió radicalmente. En la Europa medieval la ciudadanía prácticamente perdió toda su importancia. Esta representaba simplemente un privilegio del que se gozaba en una ciudad determinada, pero no dentro de un Estado. En general, la vida giraba en torno a un Rey que gobernaba, unos súbditos que obedecían y un grupo de señores feudales que dominaban a sus vasallos (Heater, 2007). Como resultado, aquella figura de ciudadano insertado en la comunidad que participaba activamente en la vida política casi desapareció y los individuos se convirtieron en súbditos sometidos a la voluntad y arbitrio del monarca sin que su pertenencia a la comunidad implicara derechos u obligaciones de tipo político-participativo.

En el siglo XVIII, de la mano de grandes pensadores como ROUSSEAU, y gracias a importantes Revoluciones como la americana y la francesa, la noción de ciudadanía volvió a tomar mucha fuerza. Solo que esta vez lo hizo ligada a un nuevo término, el de "nación". Esta combinación dio origen a un nuevo orden mediante el cual, los sujetos pasaron a ser jurídicamente iguales y la nación se convirtió en la depositaria la soberanía. Bajo este nuevo modelo, la vinculación de la ciudadanía se trasladó a la nación, y por consiguiente, ésta se convirtió en el símbolo principal de pertenencia política a un Estado. (De Lucas, 1994)

Uno de los resultados más importantes de la Revolución Francesa fue la Declaración de los Derechos de Hombre y el Ciudadano. La libertad, la propiedad y el reconocimiento de la igualdad de todos los ciudadanos ante la Ley fueron los derechos estandartes de esta declaración. Respecto a su participación política, el artículo 6 disponía que "la ley es la expresión de la voluntad general. Todos los ciudadanos pueden contribuir a su elaboración, personalmente o por medio de sus representantes. Debe ser la misma para todos, ya sea que proteja o que sancione. Como todos los ciudadanos son iguales ante ella, todos son igualmente admisibles en toda dignidad, cargo o empleos públicos (...)”.Así, los ciudadanos se convirtieron en personas liberadas de la arbitrariedad del soberano y de su sometimiento como súbditos. Superando además, la concepción del ciudadano como sujeto, únicamente, de deberes y obligaciones, para convertirse en un verdadero poseedor de derechos.

Sin embargo, como su propio nombre lo indica, la Declaración de Derechos del Hombre y el Ciudadano, efectuó una demarcación de dos categorías de sujetos dentro de un Estado: 
hombres y ciudadanos. Con ello se incorporó una diferenciación entre aquellos derechos que les corresponden a todas las personas y aquellos derechos que les pertenecen exclusivamente a quienes están vinculados a la nación. Por un lado, se colocaron los "derechos naturales y civiles", y de otro lado, se reservaron los "derechos políticos" únicamente para los ciudadanos. Para determinar quiénes pertenecían ésta categoría, se introdujeron criterios de propiedad y género, por lo que, una vez más, las mujeres, los niños, los sirvientes, los extranjeros, los mendigos y los vagabundos quedaron excluidos de la ciudadanía activa.

Durante el siglo XIX la noción de ciudadanía permaneció básicamente sobre los mismos términos. El Estado-nación fue ganando mucha fuerza y con éste un sentimiento nacionalista, por lo que la ciudadanía se vinculó también a una identidad nacional, primordialmente representada por elementos como la lengua. Los principales países de Europa iniciaron una dura campaña por nacionalizar a sus ciudadanos. La educación cívica, el servicio militar y la obligatoriedad de aprender el idioma oficial fueron los mecanismos más utilizados para afianzar una ciudadanía basada en la pertenencia a una nación.

En el siglo XX, la trágica experiencia de las guerras mundiales y otros crueles sucesos ocurridos alrededor del mundo, como la lucha de los afroamericanos en Estados Unidos o el Apartheid en Sudáfrica, propiciaron un cambio en el concepto de ciudadanía y en el criterio de otorgamiento de los derechos. A base de extender las libertades civiles y los derechos sociales a la población que vivía dentro de las fronteras de los Estados soberanos, se modificó el contenido material que la ciudadanía había tenido hasta ese momento, lo cual permitió una importante ampliación del catálogo de derechos y la desconexión de buena parte de estos al estatus de ciudadano. No obstante, es preciso aclarar que durante este periodo la relación entre ciudadanía y pertenencia al Estado-nación permaneció intacta y siguió siendo el factor determinante para la adquisición de los derechos políticos.

Durante este periodo se efectuó además, por primera vez, una definición sistemática del concepto de ciudadanía. En 1950, T.H. MARSHALL estableció que la ciudadanía es "aquel estatus que se concede a los miembros de pleno derecho de una comunidad, donde sus beneficiarios son iguales en cuanto a los derechos y obligaciones que implica" (Marshall, 2007, Pg. 37). Según su planteamiento, la ciudadanía estaba compuesta por tres tipos distintos de derechos: civiles, políticos y económico-sociales.

Sin embargo, con el paso de los años, este concepto de ciudadanía también ha evolucionado. En la actualidad el catálogo de derechos otorgados a la personas se ha ampliado aún más y la ciudadanía ha dejado de ser el factor al que se asocian todos los derechos de las personas. A día de hoy, el hombre y el ciudadano conforman dos estatus subjetivos de los que dependen dos clases distintas de derechos fundamentales: Los derechos de la personalidad, o lo que Marshall denomina derechos civiles y económico-sociales, que corresponden a todos los seres humanos. Y los derechos de ciudadanía, los cuales forman un grupo específico y reducido de derechos de orden político que corresponden exclusivamente a los ciudadanos por su vinculación a la nación. Por lo tanto, hoy en día, la ciudadanía se ha desligado de gran parte del componente de derechos y sólo los de participación política permanecen vetados a quienes no tienen un vínculo de sangre o de nacimiento con el Estado. 


\section{Definición actual de ciudadanía}

Tanto la teoría política como el derecho han definido la ciudadanía como la relación de pertenencia de una persona a una comunidad política; de la cual dependen una serie de derechos y obligaciones para con dicha comunidad (Aláez, 2006). Es en virtud de la identificación existente entre ciudadanía y nacionalidad que el Estado otorga un acervo de derechos y deberes políticos a los miembros de su comunidad nacional. Concediéndole así, al ciudadano, un estatus especial en materia de derechos y obligaciones que le corresponden por el hecho de ser miembro de una comunidad nacional determinada.

Como se desprende de la definición dada, para el Estado social y democrático actual, éstos derechos siguen estando asociados exclusivamente a la pertenencia a un Estado, como resultado de la nacionalidad. Algunos Estados, más liberales, han ampliado esta pertenencia a la inclusión territorial, a través de la incorporación del ius solis o de los derechos de naturalización, pero otros permanecen convencidos de que el ius sanguinis es el único elemento que permite la obtención del estatus de ciudadano.

Cabe mencionar que esta vinculación tan fuerte de la ciudadanía con la nacionalidad ha provocado que, con el paso de los años, estos conceptos se hayan convertido en dos hebras de un mismo hilo. El concepto actual de ciudadanía viene de la mano del de nacionalidad, como el concreto contenido político participativo que se anuda a la pertenencia del individuo a la comunidad (Ramiro, 2008). A tal punto que han llegado incluso a utilizarse de forma indiferenciada como si se tratase de sinónimos. Esto ocurre especialmente porque la nacionalidad es, a día de hoy, el mecanismo utilizado para definir cuál es el pueblo de un Estado sobre el cual se aplicarán las Leyes. Permite a los Estados distinguir con claridad quiénes son los integrantes de la comunidad política de quienes no lo son.

De esta forma, la nacionalidad constituye una cuestión previa habilitante para la obtención de la ciudadanía y el consiguiente ejercicio de los derechos políticos. Es un estatus determinante a la hora del ejercicio de los derechos puesto que es el presupuesto necesario para el ius activae civitatis. Esto implica entonces, que la definición actual que manejamos de ciudadanía determina que junto a los derechos de la persona todavía existen otros que, a pesar de estar ligados con la dignidad y el libre desarrollo de la personalidad, siguen estando restringidos y constituyen un privilegio únicamente para aquellos que poseen la máxima vinculación con el ordenamiento jurídico estatal.

\section{La aparición de una segunda categoría de ciudadanos: los denizens.}

El concepto de ciudadanía que manejan los Estados actuales y los intensos flujos migratorios internacionales han provocado la reaparición un fenómeno que, aunque parece nuevo, es tan viejo como la antigua Grecia. En Atenas, los metecos eran personas extranjeras que vivían de modo estable en la ciudad y que, a pesar de participar de la vida cotidiana al igual que los nacionales, no gozaban de los derechos de ciudadanía. De hecho, tenían que cumplir con todos los impuestos de la ciudad e incluso pagar otros especiales; pero, no gozaban de mayores derechos, por ejemplo, no podían poseer casas o tierras y sus hijos estaban impedidos de obtener la ciudadanía. (Costa y Aláez, 2008). 
Actualmente, parece ser que está sucediendo lo mismo que en la Antigua Grecia. Desde su llegada, los inmigrantes pasan a formar parte de la sociedad de acogida, participan en ella, conviven con los nacionales y contribuyen a su desarrollo, incluso pagando impuestos, pero son solamente miembros de hecho de dicha sociedad. Al no ser sujetos de pleno derecho de la comunidad, no gozan de los mismos derechos de aquellos que son ciudadanos.

Así, los inmigrantes no son ni extraños ni ciudadanos. No son citizens pero tampoco son solamente extranjeros, por lo que para ellos se ha creado una nueva categoría: los denizens. Según la definición general de este término, son denizens aquellas personas que contribuyen de manera relevante y permanente a la dinámica social y económica de nuestras sociedades pero no son ciudadanos (Costa y Aláez, 2008). En otras palabras, entre el ciudadano pleno y extranjero absoluto ha aparecido una nueva categoría de ciudadanos intermedios. Viven y trabajan de manera estable en un Estado, pero por no ser ciudadanos permanecen excluidos de los derechos políticos.

La distinción entre "hombre" y ciudadano permanece tan clara y marcada que parece imposible lograr una igualdad jurídica entre esas dos categorías que permita incluir a todos los habitantes de un Estado dentro de sólo una de ellas. Es por esta razón que los Estados han creado una condición jurídica distinta bajo el rótulo de "condición jurídica del extranjero" la cual les ha creado un espacio distinto entre ambas categorías. Se les ha otorgado un estatus que tiene un poco de ciudadanos y un poco de personas, pero sin suficientes derechos como para poder incorporarse plenamente a la sociedad en la que viven. Consecuentemente, existe una inclusión diferenciada y una institucionalización de la ciudadanía dual en los ordenamientos jurídicos estatales. (Silveira, 2003)

\section{Falencias del modelo actual de ciudadanía frente a la globalización.}

Los fenómenos de la globalización y la internacionalización del mundo están produciendo una erosión en los elementos constitutivos del Estado, por lo que un modelo de ciudadanía ligado exclusivamente a factores de tipo étnico-culturales resulta cada vez menos defendible. El Estado nación está sometido, en la actualidad, a una serie de procesos económicos, políticos y jurídicos que obligan a que la teoría constitucional deba replantear algunos de sus conceptos fundamentales, principalmente porque existe un progresivo debilitamiento de la identificación entre ciudadanía y nacionalidad. Tal y como plantea Habermas“ hoy, puesto que el Estado nacional se ve desafiado en el interior por la fuerza explosiva del multiculturalismo y desde fuera por la presión problemática de la globalización, se plantea la cuestión de si existe un equivalente igualmente funcional para la trabazón existente entre nación de ciudadanos y nación étnica" (Habermas, 2010, Pg. 94). Por ello, a continuación analizaremos las principales falencias y problemas del modelo de ciudadanía actual, para determinar cómo esas dificultades afectan especialmente a los miembros más vulnerables de las sociedades: los extranjeros.

En primer lugar, la aparición de una jerarquización de la ciudadanía y la creación de una nueva categoría de ciudadanos (denizens) demuestra que el esquema de ciudadanía que tiene como base al "Estado-nación", hoy en día no es eficaz. Tal y como sostiene Zapata - Barrero, la concepción tradicionalista y ortodoxa que se ha manejado hasta hoy "defiende la necesidad del carácter homogéneo del demos y la identidad de la ciudadanía con la nacionalidad 
(nacionalidad=ciudadanía)" (Zapata-Barrero, 2003, Pg. 116) y este entendimiento hace imposible la existencia de cualquier otro sistema, de hecho, cualquier otra opción es indeseable en términos de seguridad y cohesión. Pero hoy en día todas estas premisas se han puesto en duda como resultado de la globalización, que problematiza la conexión entre el Estado, nación y ciudadanía, evidenciando el carácter heterogéneo del demos y de la ciudadanía que, por sus características, difícilmente puede permanecer identificadas con la nacionalidad.

A día de hoy el demos de un Estado no coincide plenamente con los ciudadanos, por lo que por su carácter heterogéneo, la ciudadanía ya no representa a todos quienes pertenecen a un Estado. Por eso, ajustándonos a la realidad, para hablar de ciudadanía deberíamos hacer referencia al contacto entre la persona y el Estado. Es decir, la ciudadanía como el vínculo que permite a la persona comunicarse y relacionarse con el Estado y viceversa. Esto debido a que, en las sociedades multiculturales actuales, el individuo, sea de la nacionalidad que sea, requiere la posibilidad de participar y de poder conectar directamente con el Estado en el que vive de forma permanente.

En segundo lugar, al ser la ciudadanía una relación política en virtud de la cual el individuo es miembro de pleno de derecho de la comunidad, ésta le otorga el reconocimiento oficial de su integración en la comunidad política. Y este vínculo se convierte en una identificación social entre ciudadanos que contribuye a la construcción de su identidad personal y colectiva. Así, autores como Cortina, consideran que aquí se encuentra precisamente la grandeza y la miseria del concepto tradicional, ya que "la identificación con el grupo supone descubrir rasgos comunes, semejanzas entre los miembros del grupo y a la vez tomar conciencia de las diferencias con los foráneos. De suerte que la trama de la ciudadanía se urde con dos tipos de mimbres: la aproximación a los semejantes y la separación con respecto a los diferentes" (Cortina, 2001, Pg. 39). Es decir, la identificación que produce el concepto de ciudadanía, basado solamente en cuestiones de tipo étnico-culturales, constituye un concepto excluyente que contribuye a exacerbar sentimientos separación, discriminación o rechazo hacia quienes son distintos; ya sea por pertenecer a una raza o cultura distinta o simplemente porque, pese a no haber diferencias tan evidentes, nació en un territorio distinto.

En este sentido, el estatus de ciudadano provoca la imposición de una frontera de inclusión y exclusión del individuo, en la medida en que la ciudadanía es el factor que determina su ubicación política dentro de un Estado. El hablar de ciudadanos como destinatarios de ciertos derechos, deja fuera a muchas personas y convierte a la ciudadanía en la responsable de una desigualdad social legítima. El reconocimiento de derechos condicionados a la pertenencia o fidelidad de una determinada identidad nacional hace que la ciudadanía sea, sin lugar a dudas, un factor de exclusión y fractura social. Provocando lo que Ferrajoli ha pronosticado insistentemente, "si los derechos fundamentales se asientan sobre un concepto de ciudadanía excluyente, en el que no participan grandes sectores de la población, entonces los derechos fundamentales se convierten inevitablemente en categorías de exclusión" (Ferrajoli, 2009, Pg. 117).

Además, constituye una fórmula de cierre de la comunidad política para convertirla en una especie de club exclusivo al que, en muchos casos, puede accederse únicamente por ius sanguinis. Por tanto, lejos de ser, únicamente, un mecanismo legal y político para identificar a 
aquellos sujetos que pertenecen de forma plena a la comunidad, se ha convertido en una herramienta de discriminación y exclusión de importantes sectores de la población. De hecho, es por esta razón que Ferrajoli considera que "es preciso reconocer que la ciudadanía ya no es, como en los orígenes del Estado moderno, un factor de inclusión y de igualdad. Por el contrario ahora representa el último privilegio de estatus, el último factor de exclusión y discriminación". (Ferrajoli, 2009, Pg. 117)

Mantener un modelo excluyente de ciudadanía provoca que millones de personas se vean marginadas e impedidas de ejercer plenamente todos los derechos por el simple hecho de haber nacido en un lugar distinto al de su residencia. Los extranjeros quedan suspendidos un limbo jurídico: no son ajenos pero tampoco son parte de la comunidad; y ello no constituye una base apropiada para la consecución plena de los derechos humanos. Es necesario desvincular a la ciudadanía y los derechos que esta conlleva de la nacionalidad, pues como bien plantea Ferrajoli "a día de hoy existe la necesidad de pasar de los derechos del ciudadano a los derechos de la persona, en el sentido de ir más allá de la ciudadanía y permitir así la definitiva desnacionalización de los derechos fundamentales". (Ferrajoli, 2009, Pg. 55-56)

En tercer lugar, desde otra perspectiva, en cuanto al principio democrático y de legitimidad del Estado de derecho, es preciso mencionar que la única forma de maximizar ambos principios es permitir la participación en el ejercicio del poder a todo sujeto que esté sometido al mismo. Es una exigencia de la propia definición del principio democrático que todos quienes se encuentran subordinados a un ordenamiento jurídico concreto deben tener la posibilidad de participar de forma libre, igual y plural en la creación normativa a la que van a estar sujetos. El criterio formal de la nacionalidad como mecanismo de construcción del sujeto colectivo menoscaba la posibilidad de una óptima participación por parte de todos los sujetos que se encuentran sometidos al imperio de un ordenamiento jurídico. Sólo el ejercicio pleno de los derechos fundamentales, incluyendo los de tipo político-participativo, a todos los residentes de un Estado, con independencia de que sean nacionales o extranjeros, permitiría garantizar los pilares estructurales de los ordenamientos jurídicos actuales.

Adicionalmente, los valores democráticos actuales ponen en duda que la construcción del sujeto colectivo al que se le imputa la soberanía esté determinada únicamente por criterios de identidad étnica o racial. El carácter democrático de los Estados actuales nos obliga a cuestionar si esa vinculación necesaria entre la ciudadanía y la nacionalidad es correcta o si simplemente mantiene fuera del electorado a un grupo de personas que contribuyen y participan en el desarrollo de la sociedad.

Con la globalización y los altos niveles de movilidad demográfica, los extranjeros residentes ya no pueden ser vistos como una amenaza para la seguridad interna sino como miembros claves para el desarrollo del Estado. Sin lugar a duda, ellos también tienen intereses legítimos dentro del Estado; y por tanto, son un apoyo para el desarrollo económico y cultural de la sociedad. De modo que la nacionalidad, como requisito insalvable, para formar parte del electorado resulta injusta e infundada. Ya no estamos ante los Estados paranoicos y protectores del pasado. Quizás es hora cambiar esos rasgos tradicionales y sustituirlos por requisitos más reales y consecuentes, como el de la residencia estable y permanente en el territorio. Ello 
permitiría la posibilidad de que, sin necesidad de adquirir la nacionalidad, los extranjeros residentes puedan participar plenamente en la vida política y jurídica del país.

Es más, resulta contradictorio que por la concepción actual de la ciudadanía, haya personas que carecen de toda vinculación real con Estado por no residir en el territorio del mismo, pero que por su nacionalidad sí gozan de los derechos políticos, mientras que aquellos que están completamente vinculados al Estado en la práctica, permanecen al margen, incapaces de participar en la conformación de la voluntad soberana por no tener un vínculo de ius sanguinis. (Amores, 2009)

Por otro lado, debemos considerar el lema norteamericano de "no taxation without representation". Esta premisa nos obliga a preguntarnos si el sometimiento de los extranjeros a la imposición local y nacional en el país de residencia no debería conllevar también su derecho de participación política y el libre acceso a la totalidad de los derechos que incluye la ciudadanía (Rodríguez-Drincourt, 1997). Dado que los residentes extranjeros contribuyen a las arcas del Estado, aportan al desarrollo del país en el que residen y se ven afectados por las decisiones adoptadas por los poderes públicos, deberían estar representados y tener la oportunidad de participar activamente. De lo contrario, estamos ante una situación en la que los extranjeros son incluidos plenamente únicamente para beneficiar al Estado receptor. Es decir, los extranjeros residentes no tienen derecho a ejercer todos los derechos fundamentales, pues no gozan del estatus de ciudadano, pero aquello no les exime de estar sujetos a todas las obligaciones que emanan de la ciudadanía. Resulta un tanto contradictorio y paradójico que la ciudadanía implique restricciones en cuanto a derechos pero plena inclusión en cuanto a obligaciones.

\section{La ciudadanía inclusiva como modelo para el reconocimiento pleno de derechos de las personas.}

Todo demuestra que es preciso replantear el concepto de ciudadanía; si la globalización ha logrado desnacionalizar la economía y derribar fronteras, es imperativo que el modelo de ciudadanía se ajuste y evolucione a la altura de las circunstancias. No se puede limitar ciertos derechos fundamentales a millones de personas por el simple hecho de que no nacieron dentro del territorio de un Estado o no tienen un vínculo de sangre con él.

Un pueblo político globalizado y democrático es una asociación voluntaria heterogénea, multicultural e inclusiva en donde todos son iguales por el solo hecho de ser personas que conviven y contribuyen al desarrollo de su sociedad. La igualdad de derechos no debe estar sometida a la nacionalidad o a engorrosos procesos de naturalización, pues aquello no genera lealtad ni conexión a un Estado. La residencia habitual, la formación de una familia, la ocupación laboral, la participación activa en la comunidad y el pago de los impuestos sí son elementos reales que generan lazos, unión y lealtad; y aquellos deberían bastar para garantizar la lealtad que un Estado reclama. Los vínculos asociativos y la adhesión voluntaria a un Estado como sujeto pasivo deberían ser suficientes para admitir a un nuevo socio en la comunidad política y otorgarle el pleno reconocimiento de derechos. La incorporación de estas nuevas formas de pertenencia permitiría un nuevo modelo de ciudadanía postmarshalliana caracterizada por un proceso de "des-etnicización de la ciudadanía", donde la inclusión esté basada en la residencia y 
en el nacimiento dentro de un territorio más no en un vínculo de sangre (ius sanguinis). (López Sala, 2005. Pg 135)

Autores como Kelsen entienden que la razón por la que la ciudadanía es la condición de los derechos políticos es que éstos "son de la mayor importancia para la formación del ordenamiento jurídico, en cuanto posibilidad de participar en la creación o ejecución de dichas normas", no obstante admite que "la realidad demuestra que estos derechos no tienen por qué estar reservados sólo a los ciudadanos, porque cómo tal, la ciudadanía no es una institución necesaria para la existencia o supervivencia del Estado" (De Lucas, 1994, Pg. 140). Esto es cierto, pues si tomamos en cuenta factores empíricos, hasta aquí, no existe ninguna prueba de que el derecho de sufragio de los no ciudadanos haya socavado o atentado contra la democracia, estabilidad o seguridad de aquellos Estados en los que se la ha implantado, ni que su reconocimiento haya afectado de modo alguno a los ciudadanos originarios. Por otro lado, en el mundo existen Estados no democráticos donde no hay la figura del ciudadano como tal, pues se mantiene la figura del súbdito, que no goza del catálogo de derechos que otorga el estatus de ciudadano; pero aun así los Estados existen y perduran. Por lo tanto, bajo este planteamiento, la desvinculación de la nacionalidad y la ciudadanía no conlleva riesgo alguno para la supervivencia del Estado. Parece perfectamente posible permitir que los extranjeros residentes también puedan participar en el ejercicio de creación o ejecución del ordenamiento jurídico, sin que sean considerados como posibles rompedores de la estabilidad estatal.

En definitiva, el elemento importante para la obtención de los derechos actualmente ligados a la ciudadanía debería ser la sujeción estable a un Estado por medio de la residencia permanente. La nacionalidad no debería construirse con la intención de formar solamente un ente colectivo caracterizado por unas señas comunes de tipo étnico o cultural. Por el contrario, debería construirse con el fin de dotar de un contenido personal a un sujeto colectivo, pero con conciencia de que éste está en constante renovación y que su elemento de identidad no debe ser otro que ese deseo de permanecer de forma estable y prolongada como sujeto sometido a la Constitución y las leyes de un Estado.

Por otra parte, la desvinculación de la ciudadanía de la nacionalidad encuentra también sustento en la propia teoría general de los derechos fundamentales. Algunos intérpretes de los derechos fundamentales, como el Tribunal Constitucional español, han sostenido reiteradamente que la titularidad y ejercicio de éstos está estrechamente vinculado con la dignidad humana, por lo que es menester garantizarlos para permitir el adecuado desarrollo de la personalidad. Así, podríamos considerar que los derechos de participación política también son necesarios para la garantía de la dignidad humana y el libre desarrollo de la personalidad del individuo. Es evidente que su restricción margina y convierte en vulnerables a los grupos de inmigrantes, principalmente porque promueve la separación, el aislamiento e incluso una discriminación. Consecuentemente, su reconocimiento garantizaría efectivamente la inclusión e igualdad de todas las personas sin distinción.

Así, todo apunta a que la mejor opción para revolucionar el concepto de ciudadanía y desnacionalizar los derechos que ésta conlleva sería la sustitución del requisito de la nacionalidad por el de residencia legal y permanente. Para muchos autores este proceso se conoce como la "territorialización de los derechos" o "ciudadanía postnacional" puesto que el 
criterio de residencia toma el lugar del de nacionalidad a la hora de conferir derechos (Velasco, 2006). No obstante, alcanzar esta desnacionalización de la ciudadanía implica al menos dos requisitos:

1. Que la ciudadanía deje de estar basada en la fidelidad exclusiva a un Estado nacional;

2. Que se elimine toda referencia étnico-cultural para la adquisición y disfrute de los derechos fundamentales que emanan del estatus de ciudadano.

El primer requisito no parece tan difícil de lograr puesto que, en realidad, esto ya ocurre con la doble nacionalidad o con ciudadanías comunitarias como la europea; por lo tanto, es un paso que ya se ha dado y que no requiere de mayor esfuerzo. No obstante, para la consecución del segundo requisito si es necesario modificar el enfoque actual y despojarlo de los contenidos particularistas, especialmente de aquellos que provienen del ius sanguinis, los cuales representan el mayor mecanismo de exclusión. Para lograr la igualdad real y material de los derechos, el fundamento de la ciudadanía debe ser la participación activa en la comunidad política. En otras palabras, se debe eliminar la relación entre pertenencia y derechos que se ha manejado hasta aquí para convertirla en una pertenencia relacionada con la participación activa de un sujeto en la vida de la colectividad; de tal forma que esta sea la condición necesaria y suficiente para el reconocimiento de todos los derechos indispensables para el pleno desarrollo de las personas.

Lo único que se pretende con la desnacionalización de la ciudadanía es reformular su concepción tradicional para que pueda ser conciliable con el carácter multiétnico de los actuales Estados democráticos de derecho. Es cierto que el mero hecho de concederles los derechos tradicionalmente ligados a la ciudadanía no implica automáticamente la integración de todos en la sociedad. No obstante, el mantener apartado a un grupo de personas por no gozar de la ciudadanía si impide su integración y los mantiene en una clara marginación, puesto que no gozan de igualdad de derechos y obligaciones.

Esta propuesta no pretende hacer desaparecer el concepto de ciudadanía, ni tampoco convertirlo en un concepto universal, porque al fin y al cabo, es un concepto importante para la delimitación del colectivo que se encuentra sujeto a un Estado determinado. Está claro que la nacionalidad no es un principio universalista sino propio de cada comunidad política, el cual tiene como fin la distinción de los miembros de la asociación política. Sin embargo, es necesario replantearse el contenido de la ciudadanía e ir hacia una ciudadanía más cosmopolita. Esto no significa negar las pertenencias ni convertirlas en universales sino vincularlas a factores más apropiados. Dejar de lado la definición excluyente de ciudadanía que aparta a quienes vienen del extranjero y crear nuevos lazos basados en factores como la residencia, la participación o cuando menos, permitir una concepción plural de pertenencia que no exija una única lealtad cultural o nacional.

La ciudadanía inclusiva y cosmopolita procura que el pueblo real de un Estado goce de los derechos fundamentales a plenitud, sin limitaciones, permitiendo su participación activa, sin tomar en cuenta su vinculación sanguínea o de nacimiento. Por lo que, si cambiamos el modo de ver la ciudadanía y logramos que los derechos primen sobre la identidad nacional esto permitirá una pertenencia y lealtad real de las personas frente al Estado en el que habitan. Como sostiene Zapata-Barrero "el criterio de adquisición de derechos determina el sentimiento de pertenencia a 
una identidad y bajo este enfoque la ciudadanía se concibe como una comunidad de destino, en el sentido de que lo que importa no es el tener un origen común sino un proyecto futuro común" (Zapata-Barrero, 2003, Pg. 122). Por lo tanto, los derechos no deben otorgarse mirando al pasado y basados en un principio de herencia, sino mirando el presente, tomando en cuenta la vinculación real de la persona con el Estado.

\section{Conclusiones.}

La ciudadanía ha enfrentado distintos cambios a lo largo de la historia, pero con la llegada del Estado-nación, ésta se ligó a la nacionalidad y desde entonces su vinculación se ha arraigado cada vez más, convirtiéndose en un concepto excluyente y discriminatorio. Pese a que la globalización ha modificado, flexibilizado y desnacionalizado la economía, no ha logrado desnacionalizar la ciudadanía. Al contrario, el Estado actual reclama, cada vez más, todo su antiguo imperio.

Resulta preocupante que el modelo de ciudadanía tradicional que es, por esencia, excluyente esté tomando fuerza en la actualidad. La mundialización del mercado de trabajo está ocasionando fuertes reivindicaciones hacia el nacionalismo y el cierre de fronteras. Es lamentable que la globalización pueda romper barreras en el intercambio de bienes y servicios, pero que en cuanto a las personas permanezca cerrada a la posibilidad de integración real. El modelo de ciudadanía de Marshall ha provocado la aparición de unos ciudadanos de segunda categoría (denizens). Personas que contribuyen de manera relevante y permanente a la dinámica social y económica de nuestras sociedades pero que no cuentan con el acervo completo de derechos por el simple hecho de no ser ciudadanos.

En el mundo actual la estrecha conexión entre nación y ciudadanía no es sostenible. El demos de los Estados ya no coincide plenamente con los ciudadanos del mismo. El carácter heterogéneo y multicultural de las sociedades actuales hace que la ciudadanía no represente a todos quienes pertenecen a un Estado. Por eso, ajustándonos a la realidad, la ciudadanía no puede permanecer identificada con la nacionalidad. Es hora cambiar los rasgos tradicionales y sustituirlos por requisitos más reales y consecuentes, como el de la residencia estable y permanente en el territorio. La incorporación de estas nuevas formas de pertenencia permitiría un nuevo modelo de ciudadanía postmarshalliana caracterizada por un proceso de inclusión y de reconocimiento de derechos, basados únicamente en el hecho de ser persona y en el vínculo real entre ésta y el Estado de su residencia.

Una ciudadanía inclusiva en la que los derechos se han desnacionalizado garantiza la igualdad, el pleno reconocimiento de los derechos fundamentales, la dignidad humana y el libre desarrollo de la personalidad. Por el bien de las personas, del propio Estado, de la legitimación democrática y de la globalización, el pueblo real de un Estado debe estar representado, participar activamente sin discriminación de ninguna clase y ejercer a plenitud los derechos fundamentales. Y aquello se logra solamente a través de una ciudadanía inclusiva desligada de la nacionalidad. La ciudadanía inclusiva es un reto posible y deseable, debemos arrancar las consideraciones paranoicas y nacionalistas y abrir paso a la mundialización de los derechos de las personas. Ésta debe convertirse en la lucha de este siglo, para lograr la inclusión de todos y obtener un verdadero Estado social, democrático y de derechos. 


\section{Bibliografía}

Aláez Corral, B. (2006) Nacionalidad, ciudadanía y democracia: ¿a quién pertenece la constitución? Madrid: Centro de Estudios Políticos y Constitucionales.

Amores Conradi, M. (2009) Artículo 11. En Comentarios a la Constitución Española. Casas Baamonde, M Et Al. Madrid: Fundación Wolters Kluwer.

Bauböck, R. (2006). Lealtades rivales e inclusión democrática en contextos migratorios. Revista Internacional de Filosofía Política. 27.

Calvo Buezas, T. (2006). La emigración de trabajadores extranjeros a España: Un fenómeno nuevo y relevante en la historia de España. En hispanos en Estados Unidos, Inmigrantes en España: ¿Amenaza o nueva civilización? Madrid: Editorial Catarata.

Costa, P \& Aláez, B. (2008) Nacionalidad y ciudadanía. Madrid: Fundación Coloquio Jurídico Europeo.

Cortina, A. (2001). Ciudadanos del Mundo. Hacia una teoría de la ciudadanía. Madrid: Alianza Editorial.

De Lucas, J. (1994). El desafío de las fronteras. Derechos humanos y xenofobia frente a una sociedad plural. Madrid: Temas de Hoy.

Declaración de los Derechos del Hombre y el Ciudadano. Aprobada por la Asamblea Nacional Constituyente francesa el 26 de agosto de 1789.

Ferrajoli, L. (2009). Derechos y Garantías. La Ley del más Débil. Madrid: Trotta. Sexta edición.

Fernández Bermejo, M. (2008) Inmigración, un nuevo modelo de ciudadanía. En Inmigración, Estado y Derecho. Barcelona: Bosch.

García Inda, A. (2003) El cosmopolitismo y las nuevas fronteras de la ciudadanía”. En Inmigración y ciudadanía. Perspectivas socio-jurídicas. Martínez de Pisón, J \& Giró, J (coordinadores). Logroño: Servicio de Publicaciones de la Universidad de la Rioja.

Goig Martínez, J. (2008) Inmigración y Derechos Fundamentales. Jurisprudencia, Legislación y Políticas Migratorias en España. Madrid: Editorial Universitas Internacional.

Habermas, J. (2010). La inclusión del otro: Estudios de teoría política. Barcelona: Paidós.

Heater, D. (2007). Ciudadanía. Una breve historia. Madrid: Alianza Editorial.

Horrach Miralles, J. (2009) Sobre el concepto de ciudadanía: historia y modelos. Revista Factótum. 6. www.revistafactotum.com

López Y López, Á. (1997). Artículo 11. En Comentarios A La Constitución Española De 1978. Alzaga Villamil, O (Ed). Madrid: Cortes Generales, Editoriales De Derecho Reunidas.

López Sala, A. (2005). Inmigrantes y Estados: la respuesta política ante la cuestión migratoria. Barcelona: Anthropos. 
Marshall, T. (2007). Ciudadanía y clase social. Madrid: Alianza Editorial.

Méndez Lago, M. (2008) El reconocimiento del derecho de participación política de los inmigrantes: algunas experiencias. Revista Derechos y Libertades, 18.

Pérez Ledesma, M. (2007) La invención de la ciudadanía moderna. En De súbditos a ciudadanos. Una historia de la ciudadanía en España. Madrid: Centro de estudios políticos y constitucionales.

Pérez Vera, E. (1997) De los españoles y extranjeros. Comentario introductorio al capítulo 1 del título 1 de la Constitución. En Comentarios a la Constitución Española de 1978. ALZAGA

VILLAMIL, O (ED). Madrid: Cortes Generales, Editoriales de derecho reunidas.

Ramiro Avilés, M. (2008). El derecho de sufragio activo y pasivo de los inmigrantes, una utopía para el siglo XXI. Revista Derechos y Libertades. 18. Pg.105.

Rodríguez-Drincourt Álvarez, J. (1997). Los derechos políticos de los extranjeros. Madrid: Editorial Civitas S.A.

Silveira Gorski, H. (2003). Democracia, multiculturalidad y extranjería. En Ciudadanía, multiculturalidad e Inmigración. Zamora, J (coordinador). Pamplona: Editorial Verbo Divino.

Salazar Benítez, O. (2005). De la ciudadanía excluyente a la igualdad. En Inmigración y derechos de los extranjeros. Córdoba: Servicio de Publicaciones de la Universidad de Córdoba.

Sagarra Trias, E. (2008) Los derechos políticos de los extranjeros es España: Derecho de sufragio activo y pasivo en las elecciones municipales. En Inmigración, Estado y Derecho. Barcelona: Bosch.

Vacas Fernández, F. (2009). El principio de reciprocidad como condición del reconocimiento del derecho al sufragio de extranjeros en las elecciones municipales en España y sus implicaciones desde el derecho internacional. Derecho Migratorio y Extranjería. Lex Nova. 20.

Velasco, J. (2006) La desnacionalización de la ciudadanía. Inmigración y universalización de los derechos humanos. Una discusión sobre la universalidad de los derechos humanos y la inmigración. CAMPOY, I (ED). Madrid: Dykinson/Universidad Carlos III.

Verdu, P. (1991). Proclamación, formulación significado de la declaración de los derechos del hombre y el ciudadano de 1789. En Derechos Humanos y Revolución Francesa. Bilbao: Servicio Editorial de la Universidad del País Vasco.

Velasco, D. (2003). Ética y políticas para una ciudadanía universal. En Ciudadanía, multiculturalidad e Inmigración. Zamora, J (Coordinador). Pamplona: Editorial Verbo Divino.

Zapata- Barrero, R. (2003). Inmigración y multiculturalidad: hacia un nuevo concepto de ciudadanía. En Inmigración y ciudadanía. Perspectivas socio-jurídicas. Martínez de Pisón, J \& Giró, J (coordinadores). Logroño: Servicio de Publicaciones de la Universidad de la Rioja.

Zamora, J. (2003) Inmigración, ciudadanía y multiculturalidad. En Ciudadanía, multiculturalidad e Inmigración. Zamora, J (Coordinador). Pamplona: Editorial Verbo Divino. 
